Correction

\title{
Correction: Kaiseler, M., et al. The Impact of an Outdoor and Adventure Sports Course on the Wellbeing of Recovering UK Military Personnel: An Exploratory Study. Sports 2019, 7(5), 112
}

\author{
Mariana Kaiseler *(D), Chris Kay $₫$ and Jim McKenna® \\ Institute for Sport Physical Activity and Leisure 1, Leeds Beckett University, Leeds LS6 3QD, UK; \\ Chris.Kay@leedsbeckett.ac.uk (C.K.); J.McKenna@leedsbeckett.ac.uk (J.M.) \\ * Correspondence: M.H.kaiseler@leedsbeckett.ac.uk
}

Received: 24 May 2020; Accepted: 12 August 2020; Published: 3 September 2020

check for updates

The authors wish to make the following corrections to this paper [1]:

On page 3, Section 2.2, Paragraph 1, "The five-day MAC targets individuals that have already left the Armed Forces and uses adaptive sport and adventurous training to foster personal development and growth." should read "The five-day MAC targets individuals that have not already left the Armed Forces and uses adaptive sport and adventurous training to foster personal development and growth."

The authors would like to apologize for any inconvenience caused to the readers by these changes.

\section{Reference}

1. Kaiseler, M.; Kay, C.; McKenna, J. The Impact of an Outdoor and Adventure Sports Course on the Wellbeing of Recovering UK Military Personnel: An Exploratory Study. Sports 2019, 7, 112. [CrossRef] 